\title{
Treatment of localized post-traumatic neuropathic pain in scars with $5 \%$ lidocaine medicated plaster
}

\author{
This article was published in the following Dove Press journal: \\ Local and Regional Anesthesia \\ 19 August 2010 \\ Number of times this article has been viewed
}

\author{
Gerardo Correa-IIlanes' \\ Wilfredo Calderón ${ }^{2}$ \\ Ricardo Roa ${ }^{3}$ \\ José Luis Piñeros ${ }^{3}$ \\ Jacqueline Dote ${ }^{4}$ \\ David Medina ${ }^{4}$ \\ 'Servicio de Rehabilitación, Profesor \\ Adjunto Universidad de Chile, \\ 2Jefe Servicio Cirugía Plástica y \\ Quemados, ${ }^{3}$ Servicio de Cirugía \\ Plástica y Quemados, ${ }^{4}$ Servicio de \\ Rehabilitación, Hospital del Trabajador \\ de Santiago, Santiago, Chile
}

Correspondence: Gerardo Correa-lllanes Servicio de Rehabilitación, Hospital del Trabajador de Santiago, Ramón Carnicer I85, Providencia, Santiago, Chile

$\mathrm{Tel}+5626853160$

Fax +5626853180

Email gcorrea@achs.cl
Objective: To evaluate the use of 5\% lidocaine medicated plaster (LMP) for treating painful scars resulting from burns or skin degloving.

Patients and methods: This was a prospective, observational case series study in individuals with painful scars $<70 \mathrm{~cm}^{2}$ in area, caused by burns or skin degloving. The study included a structured questionnaire incorporating demographic variables, pain evaluation using the numeric rating scale (NRS), the DN4 questionnaire, and measurement of the painful surface area. Patients with open wounds in the painful skin or with severe psychiatric disease were excluded.

Results: Twenty-one men and eight women were studied, aged (mean \pm standard deviation) $41.4 \pm 11.0$ years, with painful scars located in the upper extremity $(n=9)$, lower extremity $(n=19)$, or trunk $(n=1)$. Eleven patients $(37.9 \%)$ had an associated peripheral nerve lesion. The scars were caused by burns $(n=13)$, degloving $(n=7)$, and/or orthopedic surgery $(n=9)$. The duration of pain before starting treatment with lidocaine plaster was $9.7 \pm 10.0$ (median 6) months. The initial NRS was $6.66 \pm 1.84$ points, average painful area $23.0 \pm 18.6$ (median 15$) \mathrm{cm}^{2}$, and DN4 score $4.7 \pm 2.3$ points. The duration of treatment with LMP was $13.9 \pm 10.2$ (median 11) weeks. After treatment, the NRS was reduced by $58.2 \% \pm 27.8 \%$ to $2.72 \pm 1.65$. The average painful area was reduced by $72.4 \% \pm 24.7 \%$ to $6.5 \pm 8.6$ (median 5) $\mathrm{cm}^{2}$. Nineteen patients (69\%) showed functional improvement following treatment.

Conclusion: LMP was useful for treating painful scars with a neuropathic component, producing meaningful reductions in the intensity of pain and painful surface area. This is the first time that a decrease in the painful area has been demonstrated in neuropathic pain using topical therapy, and may reflect the disease-modifying potential of LMP.

Keywords: chronic postsurgical pain, chronic post-traumatic pain, lidocaine medicated plaster, neuropathic pain

\section{Introduction}

Neuropathic pain arises as a direct consequence of injury or disease affecting the somatosensory system. ${ }^{1}$ Neuropathic pain may occur as a manifestation of various conditions that cause nerve damage, such as viral infections (postherpetic neuralgia), metabolic disorders (diabetes mellitus), drug-induced toxicity, inflammation, cancer, trauma, and postsurgical complications. ${ }^{2}$

Lidocaine is a local anesthetic that produces nonselective blockade of both open and inactive voltage-dependent sodium channels ( $\mathrm{NaV}$ 1.7, $\mathrm{NaV} 1.8$, and $\mathrm{NaV} 1.9)$ in excitatory membranes responsible for nerve conduction in $\mathrm{C}$ and $\mathrm{A}-\delta$ primary afferent fibers, suppressing the spontaneous and evoked abnormal activity that initiates and sustains neuropathic pain. ${ }^{3,4} 5 \%$ lidocaine medicated plaster (LMP, Versatis ${ }^{\circledR}$, Grünenthal, Germany), acts peripherally as a noninvasive topical analgesic, combining efficacy 
with minimal systemic absorption, a low risk of interaction with other medicinal products, and an excellent safety and tolerability profile. Several studies have provided evidence for the use of LMP in treating the neuropathic pain associated with postherpetic neuralgia. ${ }^{5-8}$ LMP has been included as the first-line treatment for localized peripheral neuropathic pain in many treatment recommendations for the US, ${ }^{9}$ Europe, ${ }^{10}$ and Latin America. ${ }^{11}$ Two years ago, LMP was approved by the Hospital del Trabajador de Santiago Pharmacy Committee for use in patients with post-traumatic pain.

LMP is applied to the most painful area for 12 hours each day and then removed for 12 hours, with no need for titration. The 12-hour dosage interval is based on the results of clinical trials demonstrating that a patch-free interval reduces skin exposure and prevents unwanted local effects induced by continuous occlusion of the affected skin, but provides continuous analgesia for 24 hours. ${ }^{12,13}$

The aim of this study was to evaluate the effectiveness of LMP in patients with painful scars of the post-traumatic/ postsurgical neuropathic type, caused by burns, degloving injuries, and surgical incisions.

\section{Methods}

An observational, open-label, clinical case series study was conducted in patients who had occupational diseases or had suffered accidents at work and were seen at the Hospital del Trabajador de Santiago in Chile from October 2008 to September 2009. Inclusion criteria were patients who had scars with a painful area measuring less than $70 \mathrm{~cm}^{2}$. Patients with open wounds or severe psychiatric illness were excluded.

A structured protocol was used, addressing demographic variables, diagnoses, causes of pain, and mental health. The DN4 questionnaire ${ }^{14,15}$ was used in all patients. This defines neuropathic pain as having a score of $4 / 10$ or above. The painful area was evaluated by measuring the width and length of the region in which the patient felt pain at the time of examination, and a photographic record of the affected area was obtained. In all suspected cases of peripheral nerve injury, a neurophysiologic study was carried out.

The initial dose (number of plasters) of LMP, use of co-analgesics, and concomitant drugs were recorded. In all patients, hypoallergenic adhesive tape (Micropore ${ }^{\circledR}, 3 \mathrm{M}$, St Paul, MN) was used to attach the plaster securely to the skin. The results of therapy were expressed as absolute and percentage changes in numerical rating scale (NRS), painful area, sleep quality, regained function, and return to work. Patients were checked monthly, and the protocol described above was used at each consultation. LMP therapy was considered effective if there was a reduction in NRS score of $\geq 3$ points or $\geq 50 \%$, and/or the painful area decreased by $\geq 50 \%$ compared with the start of therapy.

Each LMP contains $700 \mathrm{mg}$ of lidocaine. The amount of lidocaine systemically absorbed is very low (3\% $\pm 2 \%$ of the topical dose applied) and is directly related to the duration of application and the area of skin in direct contact with the LMP. Peak serum levels with a dose of four plasters for 12 or 24 hours, ie, in excess of the recommended dose and duration, are $225 \mathrm{ng} / \mathrm{mL}$ and $186 \mathrm{ng} / \mathrm{mL}$, respectively, which is approximately one-seventh the concentration required for an antiarrhythmic effect $(1500 \mathrm{ng} / \mathrm{mL})^{16-18}$ and 25 times less than the toxic dose $(5000 \mathrm{ng} / \mathrm{mL}) .{ }^{17,19,20} \mathrm{LMP}$ has been used in patients with heart disease and painful scars with no reports of significant side effects. ${ }^{21}$ All adverse reactions have been of mild to moderate intensity. Fewer than $5 \%$ of these led to discontinuation of treatment. Patients were informed of this risk and told that, in the event of occurrence, they should discontinue use.

All patients were suitably informed about the characteristics of the medicinal product and its side effects before starting the study, and gave their consent before being included. Side effects and treatment adherence were solicited by direct questioning at each interview. The study was approved by the Hospital del Trabajador de Santiago Ethics Committee.

The analysis of quantitative variables employed the mean, standard deviation, and maximum and minimum values. Qualitative variables were summarized in terms of absolute and percentage relative frequencies. The paired Student's $t$-test was used to compare mean values from the same patients examined at two time points during the investigation.

\section{Results \\ Demographics}

The study population consisted of 29 patients ( 21 men and 8 women) with a mean age of $41.4 \pm 11.0$ (range 23-62) years. The traumatic injuries were located on the lower limb in 19 cases $(65.5 \%)$, the upper limb in nine cases (31\%), and the trunk in one case. The underlying cause was diagnosed as burns in 13 cases (44.8\%), postsurgical scarring in nine cases (31\%), and crush and degloving injury of the extremity in seven cases $(24.1 \%)$.

\section{Pain evaluation}

Involvement of peripheral nerves was observed in 11 patients $(37.9 \%)$, ie, the superficial radial nerve in three patients, the peroneal nerve in two, the sural nerve in two, and the medial antebrachial cutaneous nerve, the palmar branch of the median nerve, the collateral palmar nerves, and the saphenous 
nerve in one patient each. Pain intensity (NRS) at the start of the study was $6.66 \pm 1.84$ (median 7 , range 4-10 points). Fifteen patients $(51.7 \%)$ had pain scores of $\geq 7$. The duration of pain prior to starting LMP treatment was $9.7 \pm 10.0$ months (median six months, range one month to 2.8 years). In seven patients $(24.1 \%)$ the duration of pain was less than three months, in 15 (51.7\%) it was 3-12 months, and in 7 (24.1\%) it was more than 12 months.

\section{Painful area and doses employed}

At the start of the study, the mean size of the painful area was $23 \mathrm{~cm}^{2}$ (median $15 \mathrm{~cm}^{2}$, range $8-70 \mathrm{~cm}^{2}$ ). In all patients, the plaster was applied to the painful area. Five patients used half a plaster and the other 24 used a quarter of a plaster daily.

\section{Presence of neuropathic pain}

Using the DN4 questionnaire, the mean score for the study population was $4.7 \pm 2.3$ points. Twenty-one patients had a score of $\geq 4$, including the 11 patients with a peripheral nerve lesion.

\section{Comorbidity}

Twenty-one patients $(72.4 \%)$ required treatment for accident-related psychiatric illness. The diagnoses were adjustment, anxiety, depressive, or mixed disorder in 13 cases, post-traumatic stress disorder in four cases, and major depression in four cases.

\section{Change in pain}

After $13.9 \pm 10.2$ weeks of treatment (median 11 weeks, range 4-45 weeks), the mean reduction in NRS was $2.72 \pm 1.64$ points (median 3 points, range $0-5$ points). This is equivalent to a reduction of $58.2 \% \pm 27.8 \%$ compared with baseline pain intensity (see Figure 1). In 22 patients $(75.9 \%)$ the NRS score fell by $\geq 3$ points; in 20 patients $(69 \%)$, the NRS score was reduced by $\geq 50 \%$ after LMP treatment (see Table 1 ), and no patient still had an NRS score of $\geq 7$. The painful area decreased by $16.5 \pm 13.7 \mathrm{~cm}^{2}$ (median $11 \mathrm{~cm}^{2}$, statistically significant by the paired Student $t$-test, $P<0.0005$ ). This is equivalent to a mean reduction of $72.4 \% \pm 24.7 \%$ (see Figure 2). In 25 patients $(86.2 \%)$, the painful area was reduced by $\geq 50 \%$ (see Table 1 ). Three patients (10.3\%) noticed a significant improvement in sleep quality, and 17 patients $(58.6 \%)$ reported significant functional recovery during LMP use (see Table 2).

\section{Comparison of patients with nociceptive and neuropathic pain}

This study relates to painful scars, not postsurgical neuropathic pain, and it is difficult to document a nerve lesion in neuropathic pain associated with a scar. However, the DN4

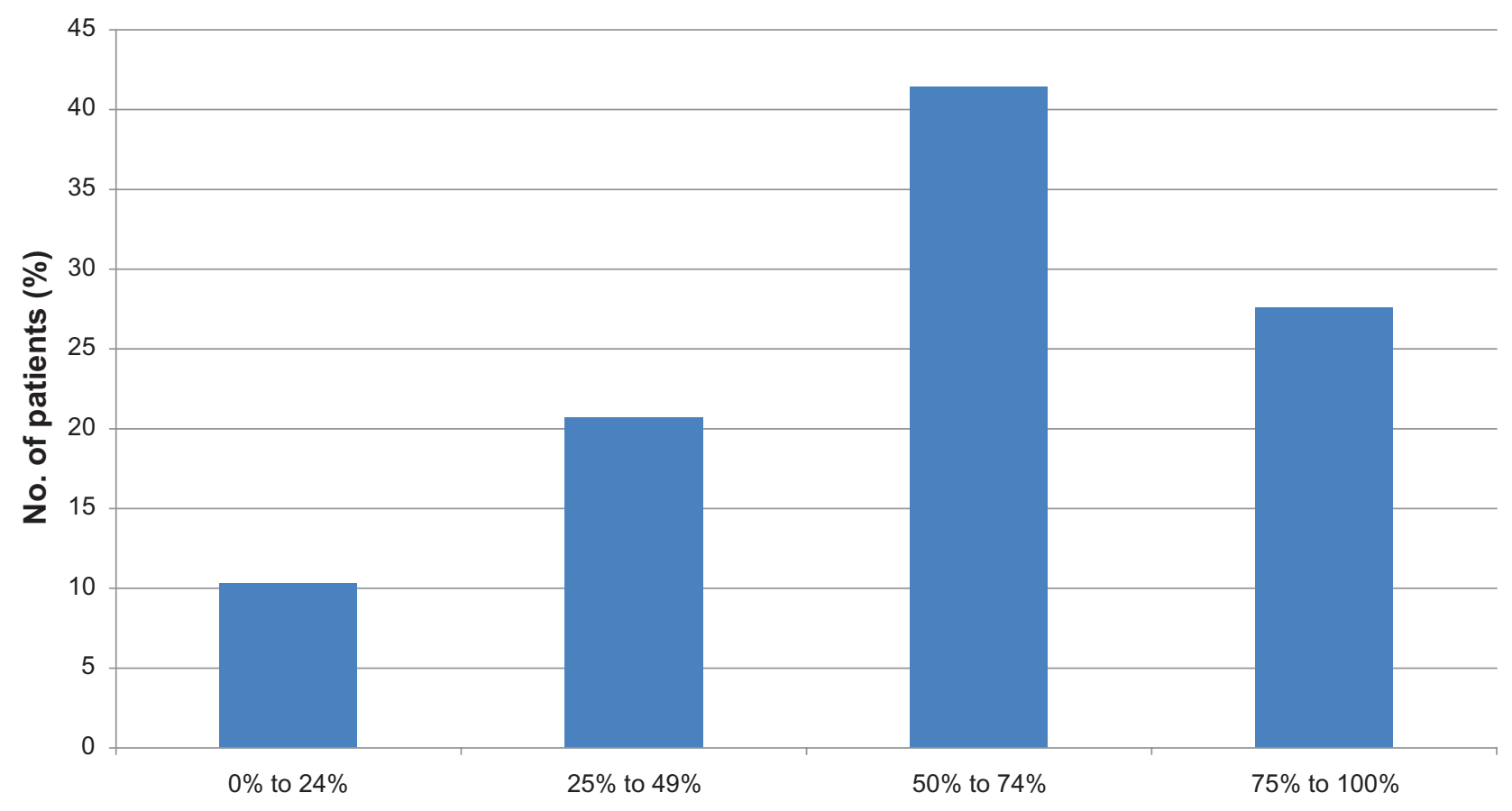

Reduction vs initial NRS score (\%)

Figure I Percentage reduction in pain score (NRS) in patients treated with $5 \%$ lidocaine medicated plaster (LMP). 
Table I Percentage reductions in pain score and painful area in patients treated with $5 \%$ lidocaine medicated plaster

\begin{tabular}{llll}
\hline $\begin{array}{l}\text { Reduction } \\
\text { versus initial } \\
\text { NRS score (\%) }\end{array}$ & $\begin{array}{l}\text { Patients } \\
(\mathbf{n}, \%)\end{array}$ & $\begin{array}{l}\text { Reduction } \\
\text { versus initial } \\
\text { painful area (\%) }\end{array}$ & $\begin{array}{l}\text { Patients } \\
(\mathbf{n}, \%)\end{array}$ \\
\hline $75-100$ & $8(27.6)$ & $75-100$ & $15(51.7)$ \\
$50-74$ & $12(41.4)$ & $50-74$ & $10(34.5)$ \\
$25-49$ & $6(20.7)$ & $25-49$ & $3(10.3)$ \\
$0-24$ & $3(10.3)$ & $0-24$ & $1(3.5)$ \\
Total & $29(100)$ & Total & $29(100)$ \\
\hline
\end{tabular}

Abbreviation: NRS, numeric rating scale.

questionnaire is an adequate clinical tool for differentiating between nociceptive and neuropathic pain. The eight patients $(27.6 \%)$ with nociceptive pain according to the DN4 questionnaire (score $<4$ ) had moderate to severe pain $(\mathrm{NRS}=6)$ and intense stabbing pain, in one case associated with allodynia.

Before starting treatment with LMP, the duration of pain was shorter in the nociceptive pain group than in the neuropathic pain group (median three months versus seven months), and the painful area was smaller (median $10.8 \mathrm{~cm}^{2}$ versus $18.0 \mathrm{~cm}^{2}$ ). The NRS scores were similar. The length of treatment until maximum pain relief was shorter in the nociceptive pain group (median 9.2 weeks versus 12 weeks). After LMP treatment, the NRS scores were similar in both groups, as were the percentage of patients that reduced their
NRS by $\geq 3$ points, the average size of the painful area, the percentage reduction in size of the painful area, and the percentage of patients with a reduction of $\geq 50 \%$ in the size of the painful area. It can be concluded that there were few differences between the two groups in their response to LMP treatment, and none was significant.

\section{Occupational impact}

Before the pain-related accident, all the patients were in active employment. Twenty-seven patients (93\%) returned to work after the accident. In patients who started LMP therapy after going back to work, functional improvement with an impact on occupational performance was observed in 12/15 cases $(80 \%$, see Table 3$)$.

\section{Change in concomitant analgesic medication}

Fourteen patients $(48.3 \%)$ were using oral analgesics, including paracetamol and tramadol, when they began treatment with LMP. No other medication was added after this point. The oral analgesics were progressively withdrawn as the patients achieved pain relief, and by the end of the study 18 patients (62\%) were using LMP therapy alone. Given that oral analgesics had been taken previously for at least three months with limited benefit, the improvement in pain relief was considered to be due to LMP therapy. Two patients were

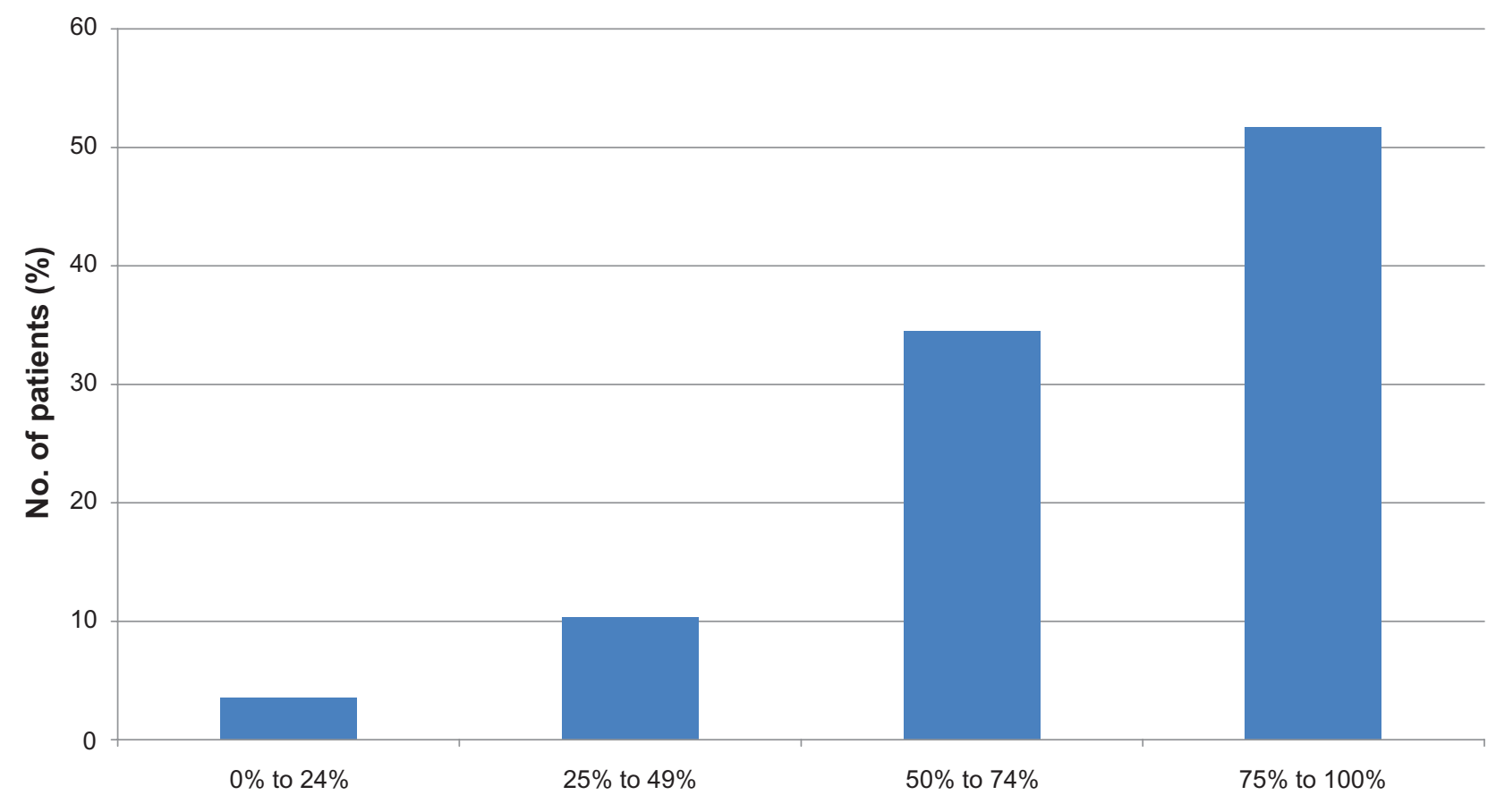

Reduction vs initial painful area (\%)

Figure 2 Percentage reduction in painful area in patients treated with $5 \%$ lidocaine medicated plaster (LMP). 
Table 2 Functional improvement in patients treated with $5 \%$ lidocaine medicated plaster

\begin{tabular}{ll}
\hline Functional aspect showing improvement & Patients (n, \%) \\
\hline Ability to walk & $8(27.6)$ \\
Daily life activities & $5(17.2)$ \\
Increased tolerance of standing & $3(10.3)$ \\
Sleep quality & $3(10.3)$ \\
Increased tolerance of upper limb prosthesis use & $2(6.9)$ \\
Increased tolerance of trunk flexion & $\mathrm{I}(3.5)$ \\
\hline
\end{tabular}

taking pregabalin (150 mg/day) when they started LMP; one discontinued its use during the study while the other continued taking it throughout.

\section{Tolerability}

None of the patients in the case series suffered any local or systemic adverse reactions to LMP use.

\section{Treatment adherence}

Patients' adherence to treatment was excellent in all cases.

\section{Discussion}

The presence of chronic pain following trauma or surgery is a common event. The exact frequency, prevalence, and natural history of these painful neuropathies are not yet known. ${ }^{21}$ According to Hans et $\mathrm{al}^{21}$ postoperative/post-traumatic neuropathic chronic cutaneous pain may follow any surgical incision. It is associated with touch-evoked allodynia, hyperalgesia, and paroxysms of spontaneous (nonevoked) pain that significantly impair the patient's quality of life, and often tends to become chronic.

The analgesic efficacy of LMP has previously been demonstrated in acute and chronic forms of peripheral neuropathy, such as postherpetic neuralgia ${ }^{22}$ and diabetic polyneuropathy. ${ }^{23}$ To date, two studies have been published on the use of LMP in post-traumatic pain. ${ }^{21,24}$ The first ${ }^{24}$ reported five cases of severe localized neuropathic scar pain, all of more than one year's duration. After 12-16 weeks, pain intensity was reduced to mild in two cases, and pain ceased completely in another two cases. In one case, pain remained at the same intensity and then ceased spontaneously. ${ }^{24}$ The second study ${ }^{21}$ evaluated the use of LMP in 40 patients with severe chronic post-traumatic cutaneous pain of surgical and nonsurgical origin. A significant reduction in pain intensity was observed at four and 12 weeks. ${ }^{21}$

The prospective study by Hans et $\mathrm{al}^{21}$ strongly suggests that LMP offers a novel therapy for postsurgical and posttraumatic localized neuropathic pain syndromes. The authors stressed that the analgesic response developed over a long period. In our study, LMP was effective in managing localized postsurgical and post-traumatic neuropathic pain. The pain relief provided by LMP improved occupational performance in two-thirds of our patients after their return to work. A high level of patient satisfaction was observed, because of ease of use and lack of side effects. Published analyses have shown

Table 3 Occupational impact of $5 \%$ lidocaine medicated plaster in active patients

\begin{tabular}{|c|c|c|c|c|}
\hline Case & $\begin{array}{l}\text { Time from returning } \\
\text { to work to starting } \\
\text { LMP (months) }\end{array}$ & $\begin{array}{l}\text { Functional improvement } \\
\text { with occupational impact }\end{array}$ & Previous job & Current job \\
\hline I & 41.6 & Working with mouth & Construction worker & Mouth artist ${ }^{\mathrm{a}}$ \\
\hline 2 & 39.2 & Ability to walk and stand & Telephone line installer & Telephone line installer \\
\hline 3 & 21.0 & $\begin{array}{l}\text { Increased functionality of } \\
\text { nondominant hand }\end{array}$ & $\begin{array}{l}\text { Advertisement } \\
\text { hoarding erector }\end{array}$ & $\begin{array}{l}\text { Advertisement } \\
\text { hoarding erector }\end{array}$ \\
\hline 4 & 18.9 & $\begin{array}{l}\text { Increased functionality of } \\
\text { nondominant hand }\end{array}$ & $\begin{array}{l}\text { Telephone line } \\
\text { repairman }\end{array}$ & Gardener $^{\mathrm{b}}$ \\
\hline 5 & 12.0 & Working with percussion tools & Maintenance mechanic & Maintenance mechanic \\
\hline 6 & 3.3 & Sleep quality & Boiler worker & Boiler worker \\
\hline 7 & 1.9 & Ability to walk & Foundry worker & Foundry worker \\
\hline 8 & 9.7 & $\begin{array}{l}\text { Increased functionality of } \\
\text { dominant hand }\end{array}$ & Garment presser & Garment presser \\
\hline 9 & 5.2 & Resumption of prosthesis use ${ }^{c}$ & Shoe factory worker & Shoe factory worker \\
\hline 10 & 5.7 & $\begin{array}{l}\text { Improved tolerance of standing, } \\
\text { squatting, going up/down stairs }\end{array}$ & Senior electrician & Senior electrician \\
\hline II & 6.1 & Improved tolerance of standing & Restaurant chef & Restaurant chef \\
\hline 12 & 2.9 & Heavy work with the dominant limb & $\begin{array}{l}\text { Transformer } \\
\text { factory worker }\end{array}$ & $\begin{array}{l}\text { Transformer } \\
\text { factory worker }\end{array}$ \\
\hline
\end{tabular}

${ }^{a}$ Amputations at both shoulders, prevented from working in a new job by painful dorsolumbar scar; bob changed for reasons unrelated to pain; 'Wrist disarticulation, unable to use prosthesis because of pain in superficial radial nerve region, underwent surgery three times without success.

Abbreviation: LMP, 5\% lidocaine medicated plaster. 
LMP to be a cost-effective method for treating localized neuropathic pain relative to pregabalin or gabapentin. ${ }^{25,26}$ However, further studies are needed to evaluate the impact of LMP and oral therapies in these patients, by comparing savings in the time taken as sick leave.

Our series differs from that of Hans et $\mathrm{al}^{21}$ because our patients had localized post-traumatic pain and were 15 years younger on average. Pain relief was higher in our study, with a $58.2 \%$ reduction in pain intensity, rather than $36 \%$. Our study also measured the painful area, which was significantly reduced in patients receiving LMP therapy. LMP has been shown to decrease the area of hyperalgesia induced by capsaicin or sunburn in healthy volunteers, ${ }^{27}$ and oral adenosine, ${ }^{28}$ mexiletine, ${ }^{29}$ and rofecoxib ${ }^{30}$ can reduce the painful area, but this is the first time the effect has been demonstrated in patients with neuropathic pain using topical therapy. Such an effect has important functional implications, especially if the painful area is located on the palm of the hand or sole of the foot. LMP may directly affect peripheral sensitization and modulate the impact of neuropathic pain. This could possibly indicate disease-modifying potential, but further investigative studies are needed.

\section{Conclusion}

In conclusion, LMP was shown to be a safe, effective treatment for localised post-traumatic or postsurgical neuropathic pain. Our results also suggest that LMP significantly improves patients' functional level, and is associated with an improvement in occupational performance. However, the study is limited by the small number of patients, a nonrandomized and open design, and lack of a placebo group, so a degree of caution should be exercised when extrapolating from these results.

\section{Case study}

This patient is a 58-year-old male, a mechanic, who suffered a high-voltage burn (12,000 volts) to his left hand which affected the collateral nerves. This trauma produced severe (NRS 8/10), persistent, neuropathic pain (DN4 9/10) in the palm of his hand, accompanied by intense allodynia. The painful surface area (outlined in blue in Figure 3) extended over $21 \mathrm{~cm}^{2}$. Pain interrupted his sleep and interfered with his work, preventing him from manipulating the tools that he had used prior to his accident. Over a period of two years and three months, the pain proved resistant to analgesic treatment. A range of analgesic drugs and schemes were tried, both singly and in various combinations, which

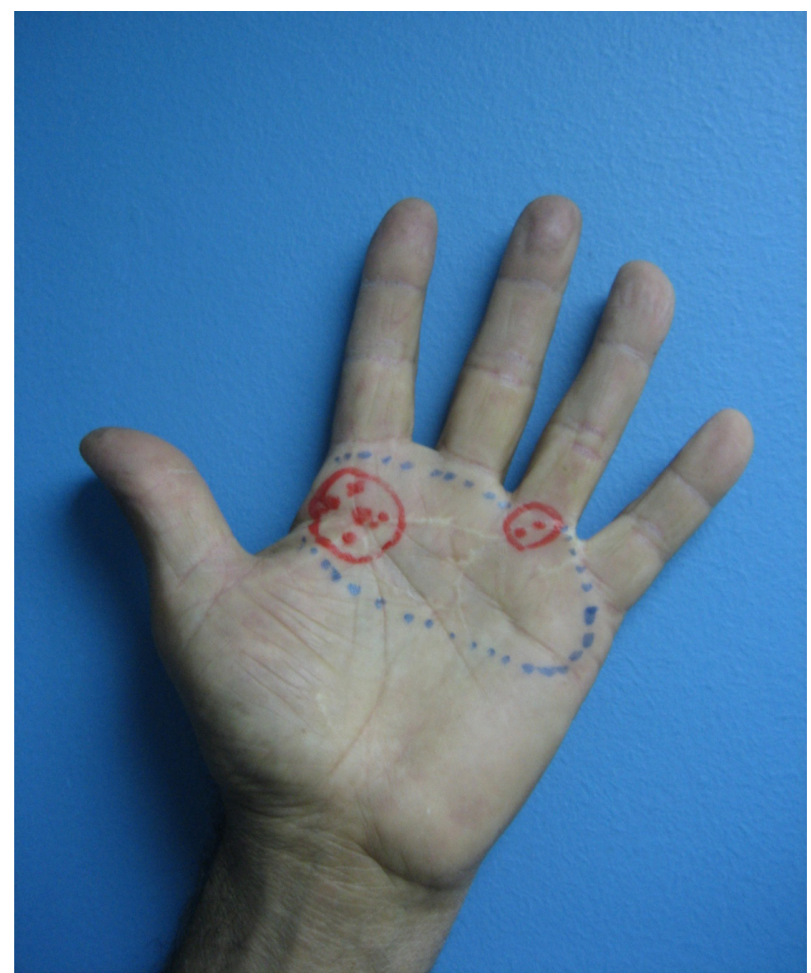

Figure 3 Painful surface area before (blue area) and after (red areas) treatment with $5 \%$ lidocaine medicated plaster (LMP).

Abbreviations: NRS, numerical rating scale; LMP, $5 \%$ lidocaine medicated plaster.

included gabapentin $400 \mathrm{mg} /$ day, tramadol $200 \mathrm{mg} /$ day, meloxicam $15 \mathrm{mg} /$ day, ketoprofen $50 \mathrm{mg} /$ day, and topical diclofenac. The dosage of gabapentin could not be increased owing to intolerance.

At this point, treatment with LMP was started. Five months later, pain intensity had reduced by $63 \%$ and the painful surface area had reduced to $4.5 \mathrm{~cm}^{2}$ overall (areas outlined in red in Figure 3). The red dots indicate discomfort rather than pain (NRS 3/10 or below) and the cross indicates pain with an NRS of 4/10 or above. Allodynia had disappeared, his quality of sleep had improved significantly, and he could now manipulate tools at work without difficulty.

\section{Acknowledgments}

We thank our superiors and colleagues in the Hospital del Trabajador de Santiago Rehabilitation Department for their assistance with this study, and Derrick Garwood Ltd, Cambridge, UK, for editorial support, which was sponsored by Grünenthal GmbH, Germany.

\section{Disclosure}

The authors report no conflict of interest in this work. 


\section{References}

1. Treede RD, Jensen TS, Campbell JN, et al. Neuropathic pain: Redefinition and a grading system for clinical and research purposes. Neurology. 2008;70(18):1630-1635.

2. Hernández JN, Hernández J, Moreno C. Use of lidocaine patches in the relief of localised neuropathic pain. Rev Iberoamericana del Dolor. 2009;1(4):13-28.

3. de Leon-Casasola OA. Multimodal approaches to the management of neuropathic pain: The role of topical analgesia. J Pain Symptom Manag. 2007;33(3):356-364.

4. Wasner G, Kleinert A, Binder A, Schattschneider J, Baron R. Postherpetic neuralgia: Topical lidocaine is effective in nociceptor-deprived skin. J Neurol. 2005;252(6):677-686.

5. Rowbotham MC, Davies PS, Verkempinck C, Galer BS. Lidocaine patch: Double-blind controlled study of a new treatment method for post-herpetic neuralgia. Pain. 1996;65(1):39-44.

6. Galer BS, Rowbotham MC, Perander J, Friedman E. Topical lidocaine patch relieves postherpetic neuralgia more effectively than a vehicle topical patch: Results of an enriched enrolment study. Pain. 1999;80: 533-538.

7. Binder A, Bruxelle J, Rogers P, Hans G, Bösl I, Baron R. Topical 5\% lidocaine (lignocaine) medicated plaster treatment for post-herpetic neuralgia: Results of a double-blind, placebo-controlled, multinational efficacy and safety trial. Clin Drug Investig. 2009;29(6):393-408.

8. Hans G, Sabatowski R, Binder A, Boesl I, Rogers P, Baron R. Efficacy and tolerability of a $5 \%$ lidocaine medicated plaster for the topical treatment of post-herpetic neuralgia: Results of a long-term study. Curr Med Res Opin. 2009;25(5):1295-1305.

9. Dworkin RH, Backonja M, Rowbotham MC, et al. Advances in neuropathic pain. Arch Neurol. 2003;60(11):1524-1534.

10. Finnerup NB, Otto M, McQuay HJ, Jensen TS, Sindrup SH. Algorithm for neuropathic pain treatment: An evidence based proposal. Pain. 2005;118(3):289-305.

11. Acevedo JC, Amaya A, de León Casasola O, et al. [Guidelines for the diagnosis and management of neuropathic pain: consensus of a group of Latin American experts]. Rev Iberoamericana del Dolor. 2008;2: 15-46.

12. Haanpää M. Mechanism-based treatment of herpes zoster and postherpetic neuralgia. Eur J Pain. 2007;11(1):38.

13. Rehm S, Binder A, Baron R. Post-herpetic neuralgia: 5\% lidocaine medicated plaster, pregabalin, or a combination of both? A randomized, open, clinical effectiveness study. Curr Med Res Opin. 2010;26(7): 1607-1619.

14. Bouhassira D, Attal N, Alchaar H, et al. Comparison of pain syndromes associated with nervous or somatic lesions and development of a new neuropathic pain diagn ostic questionnaire (DN4). Pain. 2005;114(1-2):29-36.

15. Perez C, Galvez R, Huelbes $\mathrm{S}$, et al. Validity and reliability of the Spanish version of the DN4 (Douleur Neuropathique 4 questions) questionnaire for differential diagnosis of pain syndromes associated to a neuropathic or somatic component. Health Qual Life Outcomes. 2007;5:66.
16. Benowitz NL, Meister W. Clinical pharmacokinetics of lignocaine. Clin Pharmacokinet. 1978;3(3):177-201.

17. Estes NA, Manolis AS, Greenblatt DJ, Garan H, Ruskin JN. Therapeutic serum lidocaine and metabolite concentrations in patients undergoing electrophysiologic study after discontinuation of intravenous lidocaine infusion. Am Heart J. 1989;117(5):1060-1064.

18. Jürgens G, Graudal NA, Kampmann JP. Therapeutic drug monitoring of antiarrhythmic drugs. Clin Pharmacokinet. 2003;42:647-663.

19. Gianelly R, von der Groeben JO, Spivack AP, Harrison DC. Effect of lidocaine on ventricular arrhythmias in patients with coronary heart disease. N Engl J Med. 1967;277(23):1215-1219.

20. Lie KI, Wellens HJJ, van Capelle FJ, Durrer D. Lidocaine in the prevention of primary ventricular fibrillation: A double-blind, randomized study of 212 consecutive patients. N Engl J Med. 1974;291(25): 1324-1326.

21. Hans G, Joukes E, Verhulst J, Vercauteren M. Management of neuropathic pain after surgical and non-surgical trauma with lidocaine 5\% patches: Study of 40 consecutive cases. Curr Med Res Opin. 2009; 25(11):2737-2743.

22. Davies PS, Galer BS. Review of $5 \%$ lidocaine medicated plaster studies in the treatment of postherpetic neuralgia. Drugs. 2004;64(9): 937-947.

23. Barbano RL, Hermann DN, Hart-Gouleau S, Pennella-Vaughan J, Lodewick PA, Dworkin RH. Effectiveness, tolerability and impact on quality of life of the $5 \%$ lidocaine patch in diabetic polyneuropathy. Arch Neurol. 2004;61(6):914-918.

24. Nayak S, Cunliffe M. Case report: Lidocaine 5\% patch for localized chronic neuropathic pain in adolescents: Report of five cases. Pediatric Anesthesia. 2008;18(6):554-558.

25. Liedgens H, Hertel N, Gabriel A, et al. Cost-effectiveness analysis of a $5 \%$ lidocaine medicated plaster compared with gabapentin and pregabalin for treating postherpetic neuralgia: A German perspective. Clin Drug Investig. 2008;28(9):583-601.

26. Ritchie M, Liedgens H, Nuijten M. Cost effectiveness of a 5\% lidocaine medicated plaster compared with pregabalin for the treatment of postherpetic neuralgia in the UK: A Markov model analysis. Clin Drug Investig. 2010;30(2):71-87.

27. Gustorff B. Topical lidocaine - experimental models of neuropathic pain and implications for symptomatic treatment. Eur J Pain. 2007; 11(S1):S55.

28. Sjölund KF, Segerdahl M, Sollevi A. Adenosine reduces secondary hyperalgesia in two human models of cutaneous inflammatory pain. Anesth Analg. 1999;88(3):605-610.

29. Ando K, Wallace MS, Braun J, Schulteis G. Effect of oral mexiletine on capsaicin-induced allodynia and hyperalgesia: A double-blind, placebo-controlled, crossover study. Reg Anesth Pain Med. 2000;25(5): 468-474.

30. Sycha T, Anzenhofer S, Lehr S, et al. Rofecoxib attenuates both primary and secondary inflammatory hyperalgesia: A randomized, double blinded, placebo controlled crossover trial in the UV-B pain model. Pain. 2005;113(3):316-322.
Local and Regional Anesthesia

\section{Publish your work in this journal}

Local and Regional Anesthesia is an international, peer-reviewed, open access journal publishing on the development, pharmacology, delivery and targeting and clinical use of local and regional anesthetics and analgesics. The journal welcomes submitted papers covering original research, basic science, clinical studies, reviews \& evaluations,

\section{Dovepress}

guidelines, expert opinion and commentary, case reports and extended reports. The manuscript management system is completely online and includes a very quick and fair peer-review system, which is all easy to use. Visit http://www.dovepress.com/testimonials.php to read real quotes from published authors. 